\title{
ASO Author Reflections: Outcomes for Minimally Invasive Follicular Thyroid Carcinoma in AJCC 8th Edition
}

\author{
Haruhiko Yamazaki, $\mathrm{MD}^{\mathbf{1}}$ (), Kiminori Sugino, MD, $\mathrm{PhD}^{\mathbf{1}}$, Ryohei Katoh, MD, $\mathrm{PhD}^{2}$, Kenichi Matsuzu, $\mathrm{MD} \mathrm{PhD}^{1}$, \\ Munetaka Masuda, $\mathbf{M D}, \mathbf{P h D}^{3}$, and Koichi Ito, $\mathbf{M D}, \mathbf{P h D}^{1}$ \\ ${ }^{1}$ Department of Surgery, Ito Hospital, Tokyo, Japan; ${ }^{2}$ Department of Pathology, Ito Hospital, Tokyo, Japan; ${ }^{3}$ Department \\ of Surgery, Yokohama City University School of Medicine, Yokohama City, Kanagawa, Japan
}

\section{PAST}

Most patients with follicular thyroid carcinoma (FTC) first undergo hemithyroidectomy, with a diagnosis of follicular tumor and adenomatous nodules. Completion total thyroidectomy along with radioactive iodine (RAI) therapy is not uniformly recommended for minimally invasive FTCs (MI-FTCs) without distant metastasis in Japanese revised clinical practice guidelines. ${ }^{1}$ In our hospital, completion total thyroidectomy along with RAI was recommended for patients aged $\geq 45$ years with MI-FTC, based on previous reports. ${ }^{2,3}$

\section{PRESENT}

In the American Joint Committee on Cancer (AJCC) 8th edition staging system for thyroid cancer, the stratification age was changed from 45 to 55 years, with the new staging system more appropriately reflecting the biology of thyroid cancer. ${ }^{4}$ The present study indicated that the change in stratification age as above, to recommend completion total thyroidectomy along with RAI after initial surgery, seemed to be reasonable. ${ }^{5}$
(C) Society of Surgical Oncology 2020

First Received: 6 November 2020

Accepted: 6 November 2020;

Published Online: 22 November 2020

H. Yamazaki, MD

e-mail: paruo0413@gmail.com

\section{FUTURE}

We should observe whether our recommendation improves the prognosis of patients with MI-FTC. Furthermore, we should investigate the extent of vascular invasion, which could affect prognosis in MI-FTCs, and optimal candidates for completion total thyroidectomy along with RAI.

DISCLOSURE Haruhiko Yamazaki, Kiminori Sugino, Ryohei Katoh, Kenichi Matsuzu, Munetaka Masuda, and Koichi Ito have no disclosures to declare.

\section{REFERENCES}

1. Ito $\mathrm{Y}$, Onoda $\mathrm{N}$, Okamoto $\mathrm{T}$. The revised clinical practice guidelines on the management of thyroid tumors by the Japan Associations of Endocrine Surgeons: core questions and recommendations for treatments of thyroid cancer. Endocr $J$. 2020;67(7):669-717.

2. Sugino K, Kameyama K, Ito K, et al. Outcomes and prognostic factors of 251 patients with minimally invasive follicular thyroid carcinoma. Thyroid. 2012;22(8):798-804.

3. Sugino K, Kameyama K, Nagahama M, et al. Does completion thyroidectomy improve the outcome of patients with minimally invasive follicular carcinoma of the thyroid? Ann Surg Oncol. 2014;21(9):2981-6.

4. Shaha AR, Migliacci JC, Nixon IJ, et al. Stage migration with the new American Joint Committee on Cancer (AJCC) staging system (8th edition) for differentiated thyroid cancer. Surgery 2019;165(1):6-11.

5. Yamazaki H, Sugino K, Katoh R, et al. Outcomes for Minimally Invasive Follicular Thyroid Carcinoma in the Change of Age Stratification with AJCC 8th Edition. Ann Surg Oncol. 2020. https://doi.org/10.1245/s10434-020-09397-3.

Publisher's Note Springer Nature remains neutral with regard to jurisdictional claims in published maps and institutional affiliations. 